\title{
To Estimate the Importance of Wharton's Jelly in the Growth of the Foetus - A Light Microscopic Study
}

\author{
Sreekumar Rajasekharan' ${ }^{1}$ Umesan Kannanvilakom Govindapillai², Manju Madhavan C. ${ }^{3}$, \\ Suja R. S. ${ }^{4}$, Swapna T ${ }^{5}$, Sajeena Narayanan Chitradevi ${ }^{6}$
}

1, 2, 4, 5 Department of Anatomy, Government Medical College, Thiruvananthapuram, Kerala, India. ${ }^{3}$ Department of Anatomy, Government T D Medical College, Alappuzha, Kerala, India. ${ }^{6}$ Department of Conservative Dentistry and Endodontics, NICDS, Aralumoodu, Thiruvananthapuram, Kerala, India.

\section{ABSTRACT}

\section{BACKGROUND}

Human umbilical cord contains two arteries and one vein with their tunica intima and tunica media layers. The role of tunica adventitia is fulfilled by Wharton's jelly, a mucoid connective tissue. The function of Wharton's jelly is to prevent the vessels from compression and torsion which is essential for foetal development. The purpose of the study was to estimate the importance of Wharton's jelly in the growth of the foetus.

\section{METHODS}

Umbilical cord tissue collected from each case was immediately put in $10 \%$ formalin for fixation. Slides were then stained with Haematoxylin and Eosin. These slides were then read under light microscopy and measurements were taken using a photomicrograph. Wharton's jelly area was calculated by subtracting the total vessel area from the umbilical cord area.

\section{RESULTS}

The histological measurements of umbilical vessels include the external diameter, lumen diameter, wall thickness, thickness of tunica intima and tunica media, and the area. The mean area of the umbilical cord was $35.73 \pm 23.04 \mathrm{~mm}^{2}$ (Mean \pm SD) and the mean area of the Wharton's jelly was $29.74 \pm 19.26 \mathrm{~mm}^{2}$. There was a significant difference in the external diameter and wall thickness of the umbilical artery. Analyses showed that there was a significantly $(\mathrm{P}<0.01)$ increased external diameter and wall thickness of umbilical artery in normal cases, compared to single umbilical artery cases.

\section{CONCLUSIONS}

There was a significant positive correlation between the gestational age and the external diameter of the umbilical cord. There was a significant difference in the external diameter of the umbilical cord between SUA cases $(4.45 \mathrm{~mm})$ and the other foetuses with normal umbilical cord $(6.53 \mathrm{~mm})$. There was a significantly increased external diameter, lumen diameter, wall thickness and area of umbilical vein in normal cases, compared to single umbilical artery cases. There was a significantly increased area of umbilical cord and area of Wharton's jelly in normal umbilical cord foetuses than foetuses with a single umbilical artery.

\section{KEY WORDS}

Foetus, Umbilical Cord, Wharton's Jelly, Umbilical Artery, Umbilical Vein, Light Microscopy
Corresponding Author: Dr. Manju Madhavan C., TC 13/1900 (7), Kadukkara Veedu, Koyikkal Lane, Kumarapuram, Medical College PO, Trivandrum - 695011, Kerala, India.

E-mail: manjumadhavanmch@gmail.com

DOI: $10.14260 / \mathrm{jemds} / 2021 / 617$

How to Cite This Article: Rajasekharan S, Govindapillai UK, Madhavan CM, et al. To estimate the importance of Wharton's jelly in the growth of the foetus - a light microscopic study. J Evolution Med Dent Sci 2021;10(35):3024-3029, DOI: $10.14260 /$ jemds/2021/617

Submission 21-12-2020,

Peer Review 26-06-2021,

Acceptance 02-07-2021,

Published 30-08-2021.

Copyright (C) 2021 Sreekumar Rajasekharan et al. This is an open access article distributed under Creative Commons Attribution License [Attribution 4.0 International (CC BY 4.0)] 


\section{BACKGROUND}

Umbilical cord is a structure that connects the placenta to the developing foetus, thereby providing a source of foetal nourishment. ${ }^{1}$ Bidirectional flow of blood between the mother and the foetus is established by the end of the fifth week of pregnancy through the umbilical cord. ${ }^{2}$ Human umbilical cord contains 2 arteries and one vein which comprises tunica intima and tunica media layers while lacking tunica adventitia.

The role of tunica adventitia is fulfilled by Wharton's jelly; a mucoid connective tissue described first in 1656 by Thomas Wharton. ${ }^{3}$ He said that it prevents the kinking of the vessels during the movement of the foetus in the womb. He also thought that the jelly served as a surrogate lymph transport system. The jelly contains no other blood or lymph vessels and is not innervated. These characteristics, no adventitia and no vessels other than the two arteries and vein are not typical of other species commonly used in research. ${ }^{4}$ The description of clefts within the Wharton's jelly that were considered to be the regions devoid of collagen but containing only ground substance, and thought to play an important role in the mechanical properties of the tissue. The presence of clefts provides a useful landmark when examining Wharton's jelly since they are absent from the perivascular and sub amniotic zones, but easily visible at low magnification in routine, for example, haematoxylin and eosin stains, cross-sections of cords. ${ }^{5}$

Wharton's jelly is unique among connective tissues as it contains only mesenchymal cells that comprise the functional myofibroblasts of the tissue, and their precursors. There are no other cell types described in Wharton's jelly, and no vascular or nervous elements, except the three major vessels of the cord itself. ${ }^{6}$ Meyer reported that $95 \%$ of Wharton's jelly is an extracellular matrix comprising collagen (3.6), glycoprotein (0.3), hyaluronic acid (0.31), sulfated glycosaminoglycan (0.14), and diffusible plasma proteins (1.2) - all \% wet weight. ${ }^{7}$

Umbilical vessels are embedded in the gelatinous tissue and their function is to prevent vessels from compression and torsion which is critical for proper foetal development. ${ }^{8}$ Decrease in Wharton's jelly increases the vulnerability of the blood vessels of the umbilical cord allowing compressive phenomena that leads to foetal death. ${ }^{9}$ Wharton's jelly is a specialized connective tissue composed of myofibroblasts and extracellular matrix primarily composed of proteoglycans, glycosaminoglycans and hyaluronic acid.10 Myofibroblasts are mesenchymal cells with smooth muscle cell characteristics and fibroblasts arranged amidst contents of the extracellular matrix, in which the main component $(70 \%)$ is the hyaluronic acid, an important molecule for the mechanisms of diffusion and osmosis. ${ }^{11}$

Wharton's jelly mesenchymal stem cells may be more effective than mesenchymal stem cells from adult tissues in the treatment of several conditions, and though safe and efficacious, more studies are required to justify their routine use in the clinics. ${ }^{12}$ Wharton's jelly mesenchymal stem cells use the following properties as a therapeutic potential against diabetes mellitus. They are; homing to sites of inflammation following tissue injury when injected intravenously, the secretion of multiple bioactive molecules capable of stimulating recovery of injured cells and inhibiting inflammation, modulating the immune functions, differentiation into various cell types and finally as a tool for gene therapy. ${ }^{13}$

Transplantation of Human Wharton's jelly stem cells through intravenous injection could improve the outcome of COVID-19 patients through regulating inflammatory response and promoting the recovery of antiviral immune cells and organs. ${ }^{14}$ Degenerative areas with an accumulation of mucoids (mucoid degeneration) in Wharton's jelly are not uncommon. Such degeneration may occasionally be so pronounced as to cause cyst formation. ${ }^{15}$

\section{Objectives}

(1) To measure the area of Wharton's jelly. For this initiative, the area of umbilical vessels is measured. Then the area of the umbilical cord itself is measured. Then the area of Wharton's jelly is measured by subtracting the area of umbilical vessels from the area of the umbilical cord. (2) To compare umbilical artery status i.e.; normal and single umbilical arteries based on umbilical artery measurements.

\section{METHODS}

This study was conducted from 2005 April to 2006 March. Ethical clearance for the study was obtained after submitting the informed consent form which abides by the Declaration of Helsinki and the guidelines given by ICMR. It was a descriptive, analytical study to find out the histological parameters of umbilical vessels and the umbilical cord itself to finally find out the area of Wharton's jelly. Materials used for the study consisted of foetuses sent to the Department of Pathology, Medical College, Thiruvananthapuram for autopsy. A sample size of 110 was considered for this study. Foetuses included were with a gestational age $>12$ weeks and $<40$ weeks. Also contacted the mother of the dead foetus to obtain informed consent for recruiting it in the study.

Foetus showing evidence of life (breathing, heartbeat, pulsation of umbilical cord), history of a mother taking teratogenic drugs, maternal infections (TORCH, Rubella virus, CMV and Herpes Simplex virus) during the first trimester and maternal diseases (hypertension, diabetes mellitus and chronic nephritis) were excluded from this study.

Umbilical cord tissue collected from each case was immediately put in $10 \%$ formalin for fixation. The fixed tissue bits were then subjected to routine histological processing. ${ }^{16}$ Wax blocks were prepared from the tissues. The blocks were sectioned at 0.5 microns. The slides were numbered and the key to these numbers contained the age and sex of the foetus from the specimens that were taken. Sections were carefully transferred to the surface of the water bath using a paintbrush. Then the sections on a clean glass slide were collected. Slides were then stained with haematoxylin and eosin. These slides were then read under light microscopy and measurements were taken using a photomicrograph. The size of the umbilical cord, number of umbilical vessels, the diameter of the blood vessels, the vessel wall thickness, and the lumen diameter of the vein and the arteries were recorded. The Wharton's jelly area was 
calculated by subtracting the total vessel area from the umbilical cord area.

\section{Statistical Analysis}

Considering the population of Kerala as 35,00,000 and assuming the expected frequency of cord anomalies to be 4 $\%$, the worst acceptable frequency as $0.05 \%$ and a confidence interval of $95 \%$, the sample size required was estimated to be 95. The calculation was done using the software Epi Info 2000, version 1.1.2 (CDC, Atlanta, USA). So a sample size of 110 would be considered adequate for the study with the above-said specifications. Descriptive analytical methods were used to assess the patterns of intragroup findings of arteries and veins. Similarly, students t-test or Mann Whitney U test were used to know the intra-group changes in the subjects studied.

\section{RESULTS}

The histological measurements taken were those of the umbilical arteries and the umbilical vein. The measurements were made separately for each artery and the vein. If both the umbilical arteries were present, the average measurement was considered as the arterial measurement and in the case of a single umbilical artery, the measurements from the umbilical artery were considered. The arterial measurements included the external diameter, lumen diameter, wall thickness, thickness of tunica intima and tunica media, and the area of the artery. Similar measurements were measured for the umbilical vein also. Normally an umbilical artery contains a distinct tunica intima and a prominent tunica media (Figure 1). In the case of a normal umbilical vein, tunica intima is not much prominent and tunica media is present (Figure 1). Tunica adventitia is absent in both the arteries and vein. Internal and external elastic lamina were also absent in both vessels. In one of the slides, a degenerating vessel was present, possibly a right umbilical vein. Wharton's jelly is a myxomatous supporting connective tissue of the umbilical cord. Attempts to demonstrate an elastic lamina by using special stains for elastic fibres, failed.

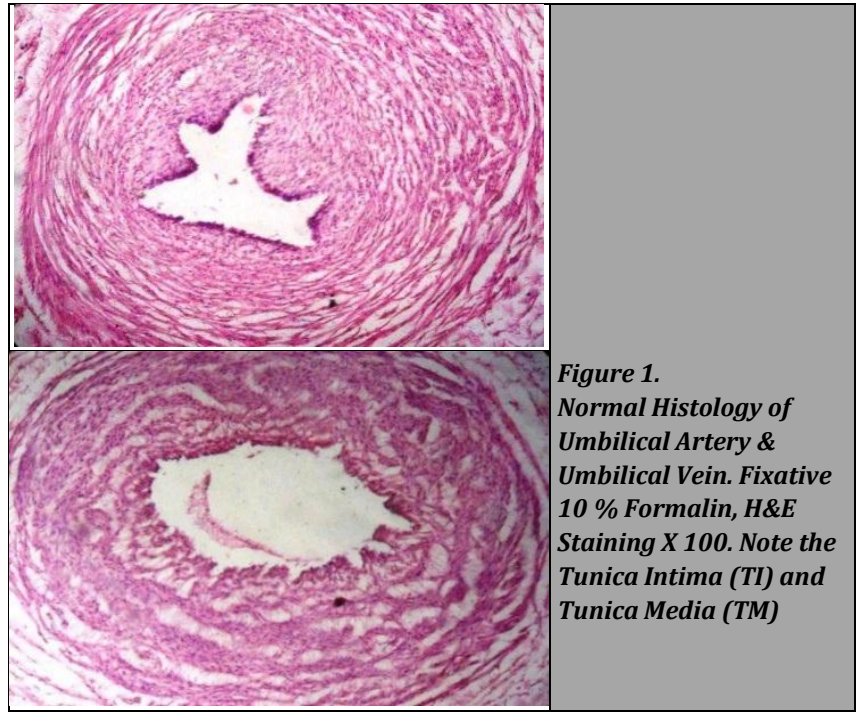

The area of the umbilical cord was calculated and from that, the area of Wharton's jelly was measured by subtracting the area of artery / arteries and the area of vein from the area of the umbilical cord. The mean arterial measurements are provided in Table 1

\begin{tabular}{|c|cc|}
\hline Parameter & N (No of Cases) & Mean \pm SD \\
\hline External diameter of artery $(\mathrm{mm})$ & 110 & $1.26 \pm 0.54$ \\
Lumen diameter of artery $(\mathrm{mm})$ & 110 & $0.63 \pm 0.47$ \\
Wall thickness of artery $(\mathrm{mm})$ & 110 & $0.32 \pm 0.17$ \\
Thickness of Tunica intima (mm) & 103 & $0.09 \pm 0.06$ \\
Thickness of Tunica media (mm) & 110 & $0.23 \pm 0.10$ \\
Area of artery (mm2) & 110 & $1.52 \pm 1.45$ \\
\hline Table 1. Mean Measurements of Umbilical Artery \\
\hline \multicolumn{2}{|c}{} \\
\hline
\end{tabular}

The measurements from the umbilical vein are provided in Table 2.

\begin{tabular}{|ccc|}
\hline Parameter & N (No of Cases) & Mean \pm SD \\
\hline External diameter of vein $(\mathrm{mm})$ & 110 & $1.88 \pm 1.10$ \\
Lumen diameter of vein $(\mathrm{mm})$ & 110 & $1.37 \pm 0.98$ \\
Wall thickness of vein $(\mathrm{mm})$ & 110 & $0.25 \pm 0.20$ \\
Thickness of tunica intima (mm) & 61 & $0.05 \pm 0.04$ \\
Thickness of tunica media $(\mathrm{mm})^{\text {Area of the vein }\left(\mathrm{mm}^{2}\right)}$ & 104 & $0.24 \pm 0.19$ \\
\hline Table 2. Mean Measurements of Umbilical Vein \\
\hline \multicolumn{2}{|l}{} \\
\hline \multicolumn{2}{|l}{} \\
\hline
\end{tabular}

The mean area of the umbilical cord was $35.73 \pm 23.04$ $\mathrm{mm}^{2}$ (Mean $\pm \mathrm{SD}$ ) and the mean area of Wharton'S jelly was $29.74 \pm 19.26 \mathrm{~mm}^{2}$.

Data were analysed to check whether there was any significant difference in the measurements of umbilical arteries and umbilical vein between the foetuses with SUA and others. The results of the umbilical artery measurements are displayed in the table below (Table 3.)

\begin{tabular}{|c|c|c|c|}
\hline Parameter & $\begin{array}{l}\text { MeaI } \\
\text { Single Umbilical } \\
\text { Artery Cases }\end{array}$ & $\begin{array}{l}\text { Normal Umbilical } \\
\text { Artery Cases }\end{array}$ & P Value \\
\hline $\begin{array}{l}\text { External diameter of artery } \\
(\mathrm{mm})\end{array}$ & $0.98 \pm 0.15$ & $1.28 \pm 0.55$ & 0.002 \\
\hline $\begin{array}{l}\text { Lumen diameter of artery } \\
(\mathrm{mm})\end{array}$ & $0.50 \pm 0.15$ & $0.64 \pm 0.48$ & NS \\
\hline Wall thickness of artery (mm) & $0.24 \pm 0.05$ & $0.33 \pm 0.17$ & 0.006 \\
\hline $\begin{array}{c}\text { Thickness of tunica intima } \\
(\mathrm{mm})\end{array}$ & $0.05 \pm 0.02$ & $0.09 \pm 0.07$ & NS \\
\hline $\begin{array}{c}\text { Thickness of tunica media } \\
(\mathrm{mm})\end{array}$ & $0.15 \pm 0.03$ & $0.23 \pm 0.11$ & NS \\
\hline Area of artery $\left(\mathrm{mm}^{2}\right)$ & $0.77 \pm 0.23$ & $1.56 \pm 1.48$ & NS \\
\hline \multicolumn{4}{|c|}{$\begin{array}{l}\text { Table 3. Umbilical Artery Measurements Based on Umbilical Artery } \\
\text { Status }\end{array}$} \\
\hline S: Not significant & & & \\
\hline
\end{tabular}

There was a significant difference in the external diameter and wall thickness of the umbilical artery. Analyses showed that there was a significantly $(\mathrm{P}<0.01)$ increased external diameter and wall thickness of umbilical artery in normal cases, compared to single umbilical artery cases. Measurements from the umbilical vein are given in Table 4.

\begin{tabular}{|c|c|c|c|}
\hline \multirow[t]{2}{*}{ Parameter } & \multirow{2}{*}{\multicolumn{2}{|c|}{$\begin{array}{c}\text { Mean } \pm \text { SD } \\
\text { Single Umbilical Normal Umbilical } \\
\text { Artery Cases } \quad \text { Artery Cases }\end{array}$}} & \multirow{2}{*}{ P Value } \\
\hline & & & \\
\hline $\begin{array}{c}\text { External diameter of vein } \\
(\mathrm{mm})\end{array}$ & $1.19 \pm 0.18$ & $1.93 \pm 1.12$ & 0.000 \\
\hline Lumen diameter of vein $(\mathrm{mm})$ & $0.88 \pm 0.23$ & $1.40 \pm 1.00$ & 0.001 \\
\hline Wall thickness of vein (mm) & $0.14 \pm 0.03$ & $0.26 \pm 0.20$ & 0.000 \\
\hline $\begin{array}{l}\text { Thickness of tunica intima } \\
\text { (mm) }\end{array}$ & --- & $0.05 \pm 0.04$ & NA \\
\hline $\begin{array}{l}\text { Thickness of tunica media } \\
\text { (mm) }\end{array}$ & --- & $0.24 \pm 0.19$ & NA \\
\hline Area of vein $\left(\mathrm{mm}^{2}\right)$ & $1.14 \pm 0.33$ & $3.51 \pm 4.14$ & 0.000 \\
\hline Table 4. Umbilical Vein & $\begin{array}{c}\text { n Measurements } \\
\text { Status }\end{array}$ & ed on Umbilice & rtery \\
\hline
\end{tabular}


There was a significantly $(\mathrm{P}<0.01)$ increased external diameter, lumen diameter, wall thickness and area of umbilical vein in normal cases, compared to single umbilical artery cases. Measurements of the area of umbilical cord and the area of Wharton's jelly are given in table 5 .

\begin{tabular}{|cccr|}
\hline Parameter & \multicolumn{2}{c|}{ Mean \pm SD } & P-Value \\
& $\begin{array}{c}\text { Single Umbilical Normal Umbilical } \\
\text { Artery Cases }\end{array}$ & \multicolumn{1}{|c|}{ Artery Cases } \\
Area of umbilical cord $\left(\mathrm{mm}^{2}\right)$ & $16.59 \pm 8.63$ & $36.83 \pm 23.14$ & 0.001 \\
Area of Wharton's jelly $\left(\mathrm{mm}^{2}\right)$ & $14.85 \pm 8.47$ & $30.60 \pm 19.38$ & 0.004 \\
\hline Table 5. Umbilical Cord Measurements Based on Umbilical Artery \\
\multicolumn{4}{|c|}{ Status } \\
\hline
\end{tabular}

Table 5 shows that there was a significantly $(\mathrm{P}<0.01)$ increased area of umbilical cord and area of Wharton's jelly in normal umbilical cord foetuses than foetuses with a single umbilical artery. There was a significant $(\mathrm{P}<0.001)$ positive correlation between the area of Wharton's jelly and the age of the foetus (Pearson's $r=0.433$ ) and the area of Wharton's jelly and weight of the foetus (Pearson's $r=0.464$ ). This shows that as the area of Wharton's jelly increases, the weight and age of the foetus also increases. Indirectly this would account for an increase in growth with an increase in the area of the Wharton's jelly.

The hypothesis that the age and weight of the foetus have in relation to the measurements of the umbilical artery and umbilical vein was evaluated. The hypothesis was generated from the assumption that an increased lumen diameter of the umbilical artery would account for an increased vascularity to the foetus, which would result in an increased growth / survival of the foetus. This was supported by the finding that there was a significantly increased age and foetal weight in cases with both umbilical arteries compared to cases with a single umbilical artery. Pearson's correlation analysis was used to understand the relation between the vascular measurements and foetal age and weight.

It was found that there exists a significantly $(\mathrm{P}<0.05)$ positive correlation between the external diameter of both the umbilical arteries and vein, the wall thickness of umbilical artery and vein, and area of the umbilical artery and area of an umbilical vein with foetal age and foetal weight. But the interesting finding is that there is no significant correlation for foetal age or foetal weight with a lumen diameter of the umbilical artery and umbilical vein. This shows that Wharton's jelly plays an important role in the growth of the foetus compared to the lumen diameter of the vasculature.

\section{DISCUSSION}

Histological measurements are taken from the umbilical arteries and the umbilical vein. If both the umbilical arteries are present then the average measurement from both arteries are considered as the arterial measurement and in the case of a single umbilical artery, the single measurement from the umbilical artery is considered. The arterial measurements include the external diameter, lumen diameter, wall thickness, thickness of tunica intima and tunica media, and the area of the artery. Similar measurements were done for the umbilical vein also.

Sexton et al. found that throughout gestation, intima of umbilical arteries and veins had a single layer of endothelial cells. ${ }^{17}$ Initially from the 8 th -15 th week, media appeared to consist mainly of circular bands of smooth muscle cells but by the 16th week, other orientations of smooth muscle cells could be observed. No clear adventitial layer and no nerves and vasa vasora were present.

The area of the umbilical cord was calculated and from that, the area of Wharton's jelly was measured by subtracting the area of vessels (area of artery/arteries + the area of a vein) from the area of the umbilical cord. Only the wall thickness, the thickness of tunica intima and tunica media, were greater in the umbilical artery and all other measurements were greater in the umbilical vein. The mean area of the umbilical cord was $35.73 \mathrm{~mm}^{2}$ and the mean area of Wharton's jelly was $29.74 \mathrm{~mm}^{2}$.

Raio et al. found that the surface cross-sectional area of Wharton's jelly was computed by subtracting the total vessel area from the cross-sectional area of the UC.18 Umbilical vessels (artery and vein) measurements were done based on umbilical artery status (normal umbilical artery and single umbilical artery). There was a significant increase in external diameter $(1.28 \mathrm{~mm})$ and wall thickness $(0.33 \mathrm{~mm})$ for the umbilical artery in normal cases, compared to single umbilical artery cases $(0.98 \mathrm{~mm}$ and $0.24 \mathrm{~mm})$. In the case of umbilical vein there was a significantly increased external diameter $(1.92 \mathrm{~mm})$, lumen diameter $(1.4 \mathrm{~mm})$, wall thickness $(0.26 \mathrm{~mm})$ and the area $\left(3.51 \mathrm{~mm}^{2}\right)$ in normal cases compared to the single umbilical artery cases $(1.19 \mathrm{~mm}, 0.88$ $\mathrm{mm}, 0.14 \mathrm{~mm}$ and $1.14 \mathrm{~mm}^{2}$ respectively). This indicates that umbilical vein measurements are more important than umbilical artery measurements regarding the number of umbilical arteries.

Malas observed that there was a positive correlation between gestational age and umbilical vessel measurements. ${ }^{19}$ There were differences between the vessel and lumen diameters, tunica media thicknesses of the vessels of 2nd and 3rd trimesters, and the full term period. There were also predictable differences between the vessel and lumen diameters, tunica media and tunica adventitia thicknesses of umbilical veins and umbilical arteries.

According to Minh et al. the tunica media contains a muscular coat that is thicker in the artery than in the veins. ${ }^{20}$ The umbilical arteries because of their thick muscular tunica can function not only as tubes for conducting blood but also as organs that regulate the blood flow.

Umbilical cord measurements including the area of the umbilical cord and the area of Wharton's jelly were also recorded based on umbilical artery status. There was a significantly increased area of the umbilical cord $\left(36.83 \mathrm{~mm}^{2}\right)$ and area of Wharton's jelly $\left(30.6 \mathrm{~mm}^{2}\right)$ in normal umbilical cord foetuses than foetuses with a single umbilical artery (16.59 $\mathrm{mm}^{2}$ and $14.85 \mathrm{~mm}^{2}$ ).

There was a significantly positive correlation between the area of Wharton's jelly and the age of the foetus (Pearson's $r$ $=0.433$ ) and the area of Wharton's jelly and the weight of the foetus (Pearson's $r=0.464$ ). This shows that as the area of Wharton's jelly increases, the weight and age of the fetus increases. Indirectly this would account for an increase in growth with an increase in the area of Wharton's jelly.

The hypothesis that the age and weight of the foetus have a relation to the measurements of the umbilical artery and umbilical vein was evaluated. The hypothesis was generated from the assumption that an increased lumen diameter of the 
umbilical artery would account for increased vascularity to the fetus, which would result in an increased growth/survival of the fetus. This was supported by the finding that there was a significantly increased age and fetal weight in cases with both umbilical arteries compared to cases with single umbilical arteries. Pearson's correlation analysis was used to understand the relation between the vascular measurements and fetal age and weight.

It was found that there exists a significantly $(\mathrm{P}<0.05)$ positive correlation between the external diameter of both umbilical artery and vein, the wall thickness of umbilical artery and vein, and area of the umbilical artery and area of the umbilical vein with foetal age and fetal weight. But the interesting finding is that there is no significant correlation for fetal age or fetal weight with a lumen diameter of the umbilical artery and umbilical vein. This shows that Wharton's jelly plays a more important role in the growth of the fetus compared to the lumen diameter of the vasculature.

Sobolewski found that Wharton's jelly is a metabolically active tissue involved in the fluid exchange between the amniotic cavity and the umbilical vessels. ${ }^{21}$ The Wharton's jelly is composed of an insoluble fibrillar network of different collagen fibres within which soluble open coil polysaccharides are held. Of these, the most represented is hyaluronic acid, which can entrap large amounts of water. A smaller part of the extracellular matrix of Wharton's jelly is formed by sulfated glycosaminoglycans, which in turn are linked to proteins to form proteoglycans.

\section{CONCLUSIONS}

There was a significant difference in the external diameter and wall thickness of normal and single umbilical artery cases. Analyses showed that there was a significantly increased external diameter and wall thickness of umbilical artery in normal cases, compared to single umbilical artery cases. There was a significantly increased external diameter, lumen diameter, wall thickness and area of umbilical vein in normal cases, compared to single umbilical artery cases.

There was a significantly increased area of umbilical cord and area of Wharton's jelly in normal umbilical cord foetuses than foetuses with a single umbilical artery. This suggests that the unnoticed entity in the umbilical cord, the Wharton's jelly carries an important role regarding the development of the umbilical cord and in turn will influence the growth of the foetus. I think this study will lay a foundation for future research works concerning the important connecting link between the foetus and the mother i.e., the umbilical cord.

Data sharing statement provided by the authors is available with the full text of this article at jemds.com.

Financial or other competing interests: None.

Disclosure forms provided by the authors are available with the full text of this article at jemds.com.

\section{REFERENCES}

[1] Davies JE, Walker JT, Keating A. Concise review: Wharton's Jelly: the rich, but enigmatic, source of mesenchymal stromal cells. Stem Cells Translational Medicine 2017;6(7):1620-30.

[2] Spurway J, Logan P, Pak S. The development, structure and blood flow within the umbilical cord with particular reference to the venous system. Australas J Ultrasound Med 2012;15(3):97-102.

[3] Stefanska K, Ozegowska K, Hutchings G, et al. Human Wharton's Jelly- cellular specificity, stemness potency, animal models and current application in human clinical trials. J Clin Med 2020;9(4):1102.

[4] Wharton TW. Adenographia. Translated by Freer S. Oxford, UK: Oxford University Press 1996: p. 1656:243.

[5] Nanaev AK, Kohnen G, Milovanov AP, et al. Stromal differentiation and architecture of the human umbilical cord. Placenta 1997;18(1):53-64.

[6] Meyer FA. Wharton's Jelly of the umbilical cord. In: Comper WD, edr. Extracellular matrix. Amsterdam: Harwood Academic Publishers 1996: p. 443-56.

[7] Lyons FG, Mattei TA. Sources, identification and clinical implications of heterogeneity in human umbilical cord stem cells. Adv Exp Med Biol 2019;1169:243-56.

[8] Kulkarni ML, Matadh PS, Ashok C, et al. Absence of Wharton's Jelly around the umbilical arteries. Indian J Pediatr 2007;74(8):787-9.

[9] Filiz AA, Rahime B, Keskin LH, et al. Positive correlation between the quantity of Wharton's Jelly in the umbilical cord and birth weight. Taiwan J Obstet Gynecol 2011;50(1):33-6.

[10] Barbieri C, Cecatti JG, Surita FG, et al. Area of Wharton's Jelly as an estimate of the thickness of the umbilical cord and its relationship with estimated fetal weight. Reprod Health 2011;8:32.

[11] Liau LL, Ruszymah BHI, Ng MH, et al. Characteristics and clinical applications of Wharton's jelly-derived mesenchymal stromal cells. Curr Res Transl Med 2020;68(1):5-16.

[12] Anzalone R, Lo Iocano M, Loria T, et al. Wharton's jelly mesenchymal stem cells as candidates for beta cells regeneration: extending the differentiative and immunomodulatory benefits of adult mesenchymal stem cells for type 1 diabetes. Stem Cell Rev 2011;7(2):34263.

[13] Wang HS, Hung SC, Peng ST, et al. Mesenchymal stem cells in the Wharton's jelly of the human umbilical cord. Stem Cells 2004;22(7):1330-7.

[14] Zhang Y, Ding J, Ren S, et al. Intravenous infusion of human umbilical cord Wharton's jelly-derived mesenchymal stem cells as a potential treatment for patients with COVID-19 pneumonia. Stem Cells Res Ther 2020;11(1):207.

[15] Bergman P, Lundin P, Malmstrom T. Mucoid degneration of Wharton's jelly - an umbilical cord anomaly threatening foetal life. Acta Obstet Gynecol Scand 1961;40(4):372-8.

[16] Slaoui M, Fiette L. Histopathology procedures: from tissue sampling to histopathological evaluation. Methods Molecular Biology 2011;691:69-82.

[17] Sexton AJ, Turmaine M, Cai WQ, et al. A study of the ultrastructure of developing human umbilical vessels. J Anat 1996;188(Pt 1):75-85.

[18] Raio L, Ghezzi F, Di Naro E, et al. Umbilical cord morphological characteristics and umbilical artery 
doppler parameters in intra uterine growth restricted foetuses. J Ultrasound Med 2003;22(12):1341-7.

[19] Malas MA, Sulak O, Gokcimen A, et al. Morphology of umbilical vessels in human foetuses: a quantitative light microscopic study. Eur J Morphol 2003;41(5):167-74.
[20] Hoang-Ngoc M, Gebrane-Younes J, Smadja A, et al. Structure and function of the foetal umbilical vessels. J Gynecol Obstet Biol Reprod (Paris) 1985;14(8):973-9.

[21] Sobolewski K, Bankowski E, Chyczewski L, et al. Collagen and glycosaminoglycans of Wharton's jelly. Biol Neonate 1997;71(1):11-21. 